\author{
VII International Forum on Teacher Education
}

\title{
Teaching Children with Dyslexia Reading in English in Artificial Language Environment
}

\author{
Svetlana N. Tatarnitseva* (a), Dana V. Gnatyuk (b) \\ (a), (b) Togliatti State University, 445020, Togliatti (Russia), 14 Belorusskaya street, \\ alyeparusa08@mail.ru
}

\begin{abstract}
The purpose of this research is to develop the techniques in teaching children with dyslexia to read in English and study their efficiency. The analysis is based on theoretical foundations of communicative, system-activity, and multisensory approaches in teaching foreign languages. The study was conducted in schools of Togliatti, the city in the Samara region in Russia. The sample comprised children aged 9-10 years with a diagnosed developmental phonological dyslexia, primary school foreign language teachers and speech pathologists. The process of acquiring reading skills in an artificial language environment was examined. The research showed that combining all senses in teaching reading in a foreign language can be effective for children with dyslexia. The significant factors are the systematic activity in practicing reading, the approach "from simple to complex", and the choice of a correct method of forming reading skills. The survey revealed that methods and techniques used in English textbooks for primary schools in Russia do not fully satisfy the needs of children with dyslexia. They do not allow the teachers to be effective enough in teaching reading. Thus, a special procedure was developed to supplement the used methods. The results of the evaluation showed that the developed procedure is effective in teaching dyslexic children reading in a foreign language.
\end{abstract}

Keywords: dyslexia, English, reading skills, language environment, the Phonic method, multisensory approach.

(C) 2021 Svetlana N. Tatarnitseva, Dana V. Gnatyuk

This is an open access article distributed under the terms of the Creative Commons Attribution License (CC BY 4.0), which permits unrestricted use, distribution, and reproduction in any medium, provided the original author and source are credited.

Published by Kazan federal university and peer-reviewed under responsibility of IFTE-2021 (VII International Forum on Teacher Education)

\footnotetext{
* Corresponding author. E-mail: alyeparusa08@mail.ru
} 


\section{Introduction}

The number of children having dyslexia has been gradually increasing in Russia and in the world during the last decades. According to the British Dyslexia Association, 10 percent of the population have dyslexia (The British Dyslexia Association, 2020). Dyslexia is not only a problem of learning difficulties. The crucial point is that children having dyslexia feel the pressure of being unsuccessful in school from early childhood, which leads to their low self-esteem, high tension and emotional instability, lack of confidence. Although there are examples of people who successfully cope with this learning difficulty and gain outstanding results being politicians, lawyers, sportsmen. However, it should be pointed out that such cases are not numerous in Russia because the problem of teaching children with dyslexia is just being aroused in the system of education in Russia. Akhutina \& Pylaeva (2012) mention that only 66\% of Russian teachers are aware of the problem of dyslexia, while seven to five percent of children have trouble with reading acquisition.

Teaching foreign languages to children with special educational needs is a difficult methodological task. Taking into account that children start learning a foreign language at the age of eight and nine, we should consider some specific psychological and physiological characteristics of students. Moreover, it seems important to analyse how to teach reading effectively in the conditions of a non-natural language environment in Russia as diminishing the role of reading within communicative approach reduces the success of the formation of a communicative competence outside the natural linguistic environment, slows down skills development (Svirina, 2008).

\section{Purpose and objectives of the study}

The authors hypothesized that foreign language teachers in Russia are not aware of the problem; they do not interact with speech pathologists working with dyslexia, and English textbooks used in modern schools in Russia do not fully meet the special needs of dyslexic children. The study aimed to prove this hypothesis and then develop the methods and techniques effective in teaching reading in English to primary school children with dyslexia. The authors attempted to describe ways, based on linguistic and didactic aspects, of how to make the process of acquiring reading in a foreign language effective in the conditions that may be named as artificial language environment, being guided by system-activity, communicative, and multisensory approaches.

\section{Literature review}


An artificial language environment is a specially organized methodical system created in accordance with the peculiarities of a natural linguocultural society (Dunaeva \& Bourina, 2019). An artificial language environment is often opposed to a natural environment when the language is acquired through constant and active but not specially organized communication. In the latter case, the person is usually naturally motivated and not strictly guided in speech activity and its development. In the artificial language environment, the teacher decides how to organize learning and which pedagogical management methods to use to provide students with the most effective learning experience. It requires a clear understanding from the teacher what individual features of the students are, what needs they have, and what abilities they possess. It is both important in general educational situations and situations involving students with special educational needs.

One of such situations concerns the problem of dyslexia. Dyslexia is defined as a specific violation of the cerebral cortex responsible for the process of reading. It leads to specific difficulties in reading such as repeated substitutions of letters, permutations, omissions (Lalayeva, 2019). The difference between the mistakes made by children with dyslexia and the mistakes made by children who are just beginning to master reading is in the typical, repetitive nature of the errors while the errors of the non-experienced reader have accidental features. In the case of children with dyslexia, these errors persist for a long time. Thus, dyslexia is determined not by a few random errors during reading but by their totality and constant nature.

While learning about the ways how to help students overcome these difficulties a teacher should study some psychological peculiarities of primary school children with dyslexia. First of all, the psychological process of attention should be taken into consideration. Speech pathologists note that younger students who are diagnosed with dyslexia most often have attention deficit disorder. This syndrome manifests itself in the process of reading by the fact that the student skips lines or words in a sentence. Moreover, attention deficit disorder is the cause of a child's disorganization, that is, children are unable to concentrate their attention on one task (Tridas, 2007).

Next, one should analyse memory characteristics, especially visual memory, which is necessary while reading and which is highly important for young learners. However, it is stated that children with developmental dyslexia have better visual memory for pictures showing superior recognition in comparison with children without dyslexia (Hedenius, Ullman, Alm, Jennische, \& Persson, 2013); they still suffer from being unable to recognize a graphic image of a word and to connect letters and sounds. The reason is in the dyslexic children's short-term memory and violation in the spatial-visual area in the cortex leading to problems in perception and data processing. To make the acquisition of the information easier it is recommended to support visual perception with tactile and kinesthetic analysers (Shaywitz, 2003). 
The thinking process of dyslexic children also has some peculiarities. Scientists revealed that dyslexic people create their own paths of data processing, very often using unusual strategies (Cancer, Manzoli, \& Antonetti, 2016), and this affects how their brains work. The brain scanning of adults with dyslexia showed that other parts of the cortex are activated during the reading process in comparison with the brains of nondyslexic adults (Shaywitz et al., 2003). Thus, a teacher should find some creative and unusual strategies to support the learner.

Dyslexia is associated with reading difficulties. Consequently, the process of reading itself and the way of training it in teaching foreign languages should be focused on.

Reading is presented as the purpose of teaching a foreign language at every stage of school education (Galskova, 2003). The acquisition of reading skills is one of the main tasks in primary school. Reading acts as a goal of teaching languages and at the same time as a learning tool. The main skill developed in primary school is reading aloud or technique of reading. Galskova (2003) defines the technique of reading as the ability of schoolchildren to quickly recognize and correlate graphic images (letters) with the corresponding auditory-motor images (sounds) and certain meanings, that is, possession of letter-sound ratios, the ability to combine visually perceived material into semantic groups or syntagmas. While the child's reading skills are being formed almost all analysers are involved, and the better they are developed, the faster the child will be able to correlate letters and letter combinations with the corresponding phonemes.

During reading acquisition, various methods such as the Alphabetic Method, the Phonic Method, the Look \& Say Method, the Sentence Method, the Whole Language Method are used. Lenskaya (1978) classifies all the methods in three groups: a) phonemic, moving from the sound to the letter; b) global, dealing with whole words or even sentences and simplified texts at an early stage; c) mixed when the choice of the way depends on the difficulty of the letter or grapheme.

The main problem of teaching reading in English is the so-called non-transparency of the language (Hengeveld \& Leufkens, 2018). In the Russian language, the letter usually makes one and the same sound in different cases. In English, reading is based on graphemes where one and the same letter in various positions and combinations makes very different sounds. It makes the process of acquiring reading techniques for dyslexic children much more complicated for they have to percept a lot of alike but different images of graphemes. Moreover, it has some crucial points when the training is carried out outside the natural language environment. While the child is growing up among native speakers he or she can hear the language every day. First, the child acquires words of the language orally and only later starts reading the words. 
Besides, the child always sees letters, words, and phrases in natural surroundings which gives the child some extra practice. Children in Russia do not have such opportunities in everyday life, because English is not spoken widely. Moreover, the Russian and English alphabetical systems are very different. Consequently, it is up to the teacher to create a friendly artificial language environment and develop a stepby-step procedure to facilitate learning for dyslexic children. The teacher acting as a mediator between the language and students designs a didactic environment, updates and expands it depending on the dynamics of learning (Dunaeva \& Bourina, 2019).

\section{Methodology}

The study is based on three approaches. The first is the system-activity approach, which implies a specially organized procedure, based on scientific research and active involvement of the students in the process (Leontyev, 2004). Asmolov (2009) indicates three main stages in implementing the system-activity approach. The initial stage is connected with the analysis of motivation and values. Thus, motivation is the main basis for meaningful activity. The next stage concerns goal setting and forming the indicative basis of the action. The last stage is related to operations and technologies, which should be set in a clear step-bystep model from knowing the basics to skills training and practicing. The second is the communicative approach which is based on the system-activity approach but analyses speech perception and production as a specific activity. Vygotskii's works on speech as activity gave the basis for the methodologists to develop the technologies of teaching a language not through drilling but through using it in different situations (Passov \& Kuzovleva, 2010; Vygotskii, Hanfmann, Vakar, \& Kozulin, 2012). The third approach is the multisensory approach which claims that active use of all analysers in the process of education is the most effective, especially for young learners. It supposes acquiring information through visual, auditory, tactile, kinaesthetic, and other ways.

The research was conducted in Togliatti (Samara region, Russia). The sample comprised twelve 9-10-year old children with diagnosed developmental dyslexia, primary school teachers, and speech pathologists. The results were analysed and interpreted on the basis of comparing the data obtained at pre-training and posttraining stages.

At the pre-training stage, we first circulated two open-ended questionnaires (OEQ): OEQ 1 to primary school teachers and OEQ 2 - to speech pathologists. All the questionnaires were developed by the authors of the study. The content validity of the questionnaires is confirmed by the main indicators of its reliability on the basis of internal consistency, clear instructions, the presence of questions to test all aspects of understanding of dyslexia and reading difficulties. 
The pragmatic validity relies on the presence of an external parameter that correlates with the questions, namely the students' grades at school. The aim of the questionnaires was to reveal the awareness of the problem of dyslexia among specialists and the ways to help children with special needs. The participation was voluntary, so all the specialists who had sent their answer sheets were taken to be willing to participate in the study. We received 20 primary school teachers' answer sheets and five speech pathologists.

Another line of the pre-training stage was connected with the analysis of the primary English textbooks in order to check how reading skills are formed and whether these textbooks are helpful for dyslexic children. We examined three textbooks recommended for teaching English in primary education approved by the order of the Ministry of Education of the Russian Federation (Ministry of Education of the Russian Federation, 2020).

At last, the pre-test of the children's reading skills was conducted in the pre-training stage. The children (and their parents) were advised to attend our classes by their speech pathologists who were involved in the study. In the first meeting, the children were given an individual reading sample comprising a set of words based on the primary school program, grade 2. The words were distributed in 4 groups "Short vowels", "Long vowels", "Digraphs", "Combinations", each group contained 10 words, the total set included 40 words. There was no time limit though the reading speed was under control as well as reading accuracy.

The training stage based on the specially developed set of methods and techniques was conducted during 1.5 years in individual work and in micro-groups.

The post-training stage included: 2 other open-ended questionnaires with the teachers (OEQ 3) and the speech pathologists (OEQ 4), working with the students who had been involved in the training stage; oral conversations with the parents of the students; a diagnostic test (post-test); and interpretation of the results. The aim of the questionnaires and conversations at this stage was to reveal the possible changes in children's attitudes to reading in English and in their reading skills. All the consents at this stage were taken from the participants in a written form; the questions were approved by a special session of the ethical council of the Institution of Humanities TGU.

The post-test was conducted following the same principles as the pre-test with the only difference that the set of English words for reading was based on the 2nd-grade program with the most frequent words of the 3rd-grade textbooks. The configuration of the test and the procedure was the same.

\section{Results}


Having analysed OEQ 1, we found that $45 \%$ of the teachers of English had heard about dyslexia, had read some articles about it; $20 \%$ of teachers supposed that they had dyslexic children in the class; $70 \%$ found it difficult to understand if reading errors were occasional, or the reason might be connected with dyslexia. None of the respondents knew exactly how to help children learn to read. Meanwhile, speech pathologists (OEQ 2) marked down that the number of children with this problem was increasing. However, as they worked with children in Russian, they could give very few ideas on how to teach them to read in English.

To understand how existing English textbooks help teachers train reading skills, the authors have analysed three most used textbooks recommended for teaching English in primary education (Biboletova, Dobrynina, \& Trubaneva, 2013; Bykova, Dooley, Pospelova, \& Evans, 2013; Komarova, 2013). All the student's books are for the first-year learners when training reading skills starts. The results of the analysis are shown in Table 1.

Table 1. Results of the analysis of reading methods and techniques described in English textbooks

\begin{tabular}{|c|c|c|c|}
\hline $\begin{array}{c}\text { The title (author) of the } \\
\text { textbook }\end{array}$ & $\begin{array}{c}\text { Brilliant } \\
\text { (Komarova) }\end{array}$ & $\begin{array}{c}\text { Enjoy English } \\
\text { (Biboletova et al) }\end{array}$ & $\begin{array}{c}\text { Spotlight } \\
(\text { Bykova et al) }\end{array}$ \\
\hline $\begin{array}{l}\text { Method of forming } \\
\text { reading skills }\end{array}$ & $\begin{array}{l}\text { Alphabetical Method } \\
\text { (letter to sound) }\end{array}$ & $\begin{array}{c}\text { Mixed-Method } \\
\text { (Phonic + Whole } \\
\text { words + Reading } \\
\text { Rules) }\end{array}$ & $\begin{array}{l}\text { Mixed-Method } \\
\text { (Alphabetical + } \\
\text { Whole words) }\end{array}$ \\
\hline $\begin{array}{c}\text { Order of sounds and } \\
\text { letters }\end{array}$ & $\begin{array}{l}\text { First consonants, } \\
\text { then vowels }\end{array}$ & $\begin{array}{c}\text { From letters that } \\
\text { remind Russian to } \\
\text { new letters and } \\
\text { sounds }\end{array}$ & $\begin{array}{l}\text { Sounds-letters-letter } \\
\text { combinations }\end{array}$ \\
\hline $\begin{array}{c}\text { Number of letters/sounds } \\
\text { per one letter }\end{array}$ & 4 & 1 & $8-9$ \\
\hline Techniques and tasks & $\begin{array}{c}\text { Listen and repeat } \\
\text { Matching }\end{array}$ & $\begin{array}{l}\text { Listen and read } \\
\text { What is missing? } \\
\text { Choose and read } \\
\text { Read and answer } \\
\text { the question }\end{array}$ & $\begin{array}{l}\text { Missing letter } \\
\text { Read and match }(+ \\
\text { additional module } \\
\text { "First steps to } \\
\text { reading") }\end{array}$ \\
\hline $\begin{array}{l}\text { Positive features for } \\
\text { dyslexic children }\end{array}$ & $\begin{array}{l}\text { Bright, lots of visual } \\
\text { aids, meets age } \\
\text { requirements }\end{array}$ & $\begin{array}{l}\text { Introductory } \\
\text { phonetic course, } \\
\text { from simple to } \\
\text { complex, enough } \\
\text { exercises }\end{array}$ & $\begin{array}{l}\text { Illustrated letters, } \\
\text { additional exercises }\end{array}$ \\
\hline $\begin{array}{l}\text { Negative features for } \\
\text { dyslexic children }\end{array}$ & $\begin{array}{l}\text { Insufficient volume of } \\
\text { introductory phonetic } \\
\text { course, a large number of } \\
\text { sounds for one lesson, }\end{array}$ & $\begin{array}{l}\text { Few exercises on } \\
\text { listening, } \\
\text { overloaded with } \\
\text { the Russian }\end{array}$ & $\begin{array}{l}\text { Insufficient volume } \\
\text { of introductory } \\
\text { phonetic course, a lot } \\
\text { of sounds for one }\end{array}$ \\
\hline
\end{tabular}




$\begin{array}{ccc}\begin{array}{c}\text { diphthongs in words } \\ \text { from the first pages, the } \\ \text { lack of exercises to }\end{array} & \begin{array}{c}\text { language (difficult } \\ \text { for dyslexics to } \\ \text { switch) }\end{array} & \begin{array}{c}\text { lesson, the lack of } \\ \text { exercises to develop } \\ \text { basic reading skills }\end{array} \\ \begin{array}{c}\text { develop basic reading } \\ \text { skills }\end{array} & & \end{array}$

Thus, we can state that training reading skills is insufficient in the first year of learning English in Russian primary schools even for children without dyslexia. It is more complicated for children diagnosed with dyslexia.

The results of the pre-test showed that $90 \%$ of children, boys and girls equally, could not read words with more than three letters; they did not distinguish between the following pairs of letters: b-d, p-d, q-p, m-n, ij. A very slow reading speed with many errors was recorded.

Taking the results of literature analysis and the pre-training stage into account, the authors have developed our own set of exercises that can be used as an additional resource to the main textbook. These exercises were based on the "playing" activity so that the training took place with less emotional stress. The set of exercises is based on the principle "from simple to complex". It includes three stages according to the system-activity approach.

The first stage is introductory and called "Knowing the Alphabet". Acquaintance with the letters starts with a clear motivational situation in a game form: to meet the letter and learn "who lives in its family" (words starting with this letter). Then, orientation takes place on the basis of the multisensory approach. Children see the letter, hear how it sounds and then start sculpting the letter using clay (visual, acoustic, and kinaesthetic analysers). Blue clay is used for consonants, and red - for vowels, which gives additional support in differentiating the letters. While sculpting, the child pronounces the letter and the sound repeatedly after the teacher or the speaker, activating kinaesthetic and acoustic analysers. Besides, the words with this letter/sound are repeated as well. Then, the child continues with the task on writing the letter. The letter is written in three squares. The first square shows how the given letter is spelt using the arrows. The second one offers to colour the letter. In the last square, the child must connect the numbers in order to get the given letter. At the bottom of the sheet, there is a line in which the child must write the learned letter. The final exercise in this section focuses on practicing all the letters of the alphabet. All letters are printed in a large size and mixed together. The student is asked to first lay out the letters in alphabetical order. Next, we find all the vowels. After the child names them, the teacher removes them from the alphabetical row and asks the child to name the remaining letters. Finally, the teacher removes some letters, both consonants and vowels, and the student should remember which letter is missing and then put it in the correct place. 
The second stage focuses on the sounds. The exercises in this section are based on the Phonic Method. Before starting to learn each phoneme, a short story is told, which contains a large number of words with a given phoneme, so that the child can highlight the repetitive sound. Next, we ask children to underline the words that contain this sound and pronounce them. After underlining the words, it is proposed to colour the picture where there is an object in the form of the sound (like "snake" for [s]). After that, an exercise is proposed where the student needs to connect the sound with objects that begin with the letter. In the concluding exercise, the student is given a large printed phoneme and some words. The child needs to put the words starting with this sound and pronounce these words. It should be noted that at the second stage, the sounds are learned in isolation from each other.

The third stage is aimed at ensuring that students can combine the phonemes with each other. First, monosyllabic words are given so that children understand how to connect sounds together as well as consolidate a closed sound. For this, the formula "CVC" is used, where "C" is a consonant and "V" is a vowel. For example, a series of the following words is given, where only the first sound changes: bat, fat, hat, lat, sat. It is worth noting that these combinations are best composed of individual letters so that the student has the opportunity to touch the letters, name the sound of this letter, and then, make various combinations of them. Further, the exercise becomes more difficult and the formula "CVCe" is used, which allows children to work out the vowels in an open syllable. For example, pine, mine, bite, kite. Finally, words that have the formula " $\mathrm{C}+\mathrm{LE}$ " are practiced. This construction occurs in the following words: bubble, double, marble, battle, little, apple, ankle.

Thus, the designed set of exercises represent the combination of approaches and the principle of gradual complication of the studied material to provide dyslexic children with the optimum training of reading skills.

The set of exercises was used step-by-step during the training period; each part of the set was practised during 6 months. The children demonstrated slow but steady progress in reading.

At the end of this period, the post-test was conducted. Table 2 shows the number of children who took part in the study with gender specifications. There were 12 children, five boys and seven girls. Two aspects were evaluated. The first one was reading accuracy, where the average percentage of the correctly read words was calculated at the pre- and post-test. The second aspect was the average reading speed measured in minutes.

Table 2. Pre-test and post-test reading results 


\begin{tabular}{ccccc}
\hline Participants (number) & \multicolumn{2}{c}{$\begin{array}{c}\text { Average Reading Accuracy } \\
\text { (\%, out of 40 words) }\end{array}$} & \multicolumn{2}{c}{$\begin{array}{c}\text { Average Reading Speed } \\
\text { (min.) }\end{array}$} \\
\cline { 2 - 5 } & Pre-Test & Post-Test & Pre-Test & Post-Test \\
\hline Boys (5) & 38,5 & 60,5 & 7 & 5 \\
Girls (7) & 44 & 69 & 6,5 & 5,5 \\
Total (12) & 41,25 & 64,75 & 6,75 & 5,25
\end{tabular}

The final test showed that the reading accuracy improved by an average of $23.5 \%$ while the reading speed increased by $22 \%$ ( $1.5 \mathrm{~min}$. faster on the post-test in comparison with the pre-test). The boys showed better results in the speed but the girls produced a quicker reading accuracy improvement.

After the training, the students showed the ability to read monosyllabic and disyllabic words. The reading technique grew in comparison with the pre-training stage, but at this stage, it did not fully correspond to the standards required by the programme of primary school. Reading errors remained but their number decreased, and they ceased to be repetitive. The largest number of mistakes was performed in the sections "Combinations" and "Long vowels", which are the most difficult for dyslexic children, as they contain digraphs and silent letters.

The post-training questionnaires verified the positive changes. For example, the teachers of the students marked down that the children felt more confident while reading, they stopped being afraid and made significantly fewer mistakes when reading familiar words, which had been difficult before. The parents of the children also said that they started doing their home tasks more independently, did not refuse to practice reading aloud at home. Three girls and one boy were eager to sculpt the letters and new words as objects, and their improvement was the most prominent. In general, girls according to the feedback of the teachers and parents demonstrated a higher level of industriousness and consequently, quicker results in reading skills improvement.

\section{Discussion}

The research confirms that dyslexic children have peculiarities, both positive and negative, which affect the process of acquiring reading skills. Learning in an artificial language environment does not let them quicker overcome the problem of slow reading skills formation with many difficulties. Consequently, they need some specially designed materials to help them learn how to read in a foreign language.

At the same time, it should be indicated that the designed set of exercises has been tested on a selected number of students. We noticed that the exercises were more effective with the children having such kind of dyslexia as phonological while children having other types showed lower results. 
Therefore, the study can be continued in the way of researching other strategies and designing new models of their assessment on a bigger number of children.

Also, there is still a problem of how to reconcile this model with existing student's books so that the child feels confident in class.

Besides, there is some discussion about the methods chosen. We combine Alphabetic and Phonic Methods, meanwhile, some methodologists insist on the Whole Word Method (Rowse \& Wilshire, 2007), as it uses pictures, and dyslexic children are proficient in recognizing them. We can object to it because this way is effective in a natural language environment, but in an artificial one, it can be quite difficult as this method requires training reading after oral speech has gained at least an elementary level of communication, and the vocabulary of a child is rich enough.

The limitation of the study can be mentioned as a relatively insufficient number of participants who took part in the training process ( 12 children). The research should be continued with a wider sample to get more valid results to prove effectiveness statistically.

However, the research results convince us that the main strategies in teaching dyslexic children reading in a foreign language are the next: systematic activity followed by communicative and multisensory approaches; a principle "from simple to complex"; game form and motivating giving a child confidence, psychological comfort and feeling of being successful.

\section{Conclusion}

Thus, dyslexia is a complex psychological, methodological and linguodidactic problem that must be treated by the efforts of scientists, speech pathologists, methodologists, teachers, and children themselves. Cooperating and well-designed materials can shorten the time and efforts spent on training reading.

The results prove the chosen methods and techniques to be effective. Many of the exercises aroused interest in the students, and they also tried to achieve high results by doing their homework. The procedure can be introduced into the process of teaching children with dyslexia to read in primary school.

\section{Funding}

The authors have no funding to report.

\section{Competing interests}


The authors have declared that no competing interests exist.

\section{Acknowledgements}

The authors have no support to report.

\section{References}

Akhutina, T. V., \& Pylaeva, N. N. (2012). Overcoming learning disabilities. New York: Cambridge University Press.

Asmolov, A. G. (2009). System-activity approach to developing standards of new generation. Pedagogy, 4, 18-22.

Biboletova, M. Z., Dobrynina, N. V., \& Trubaneva, N. N. (2013). Enjoy English 2. Student's book. Moscow: Titul.

Bykova, N. I., Dooley, J., Pospelova, M. D., \& Evans, V. (2013). Spotlight 2. Student's book. Moscow: Prosveshcheniye.

Cancer, A., Manzoli, S., \& Antonetti, A. (2016). The alleged link between creativity and dyslexia: Identifying the specific process in which dyslexic students excel. Cogent Psychology, 3, 1-14.

Dunaeva, L., \& Bourina, H. (2019). Designing artificial environment for teaching communication in a foreign language. ICERI2019 Proceedings, 857-860.

Galskova, N. D. (2003). Modern Methodology of teaching foreign languages. Moscow: ARKTI.

Hedenius, M., Ullman, M. T., Alm, P., Jennische, M., \& Persson, J. (2013). Enhanced recognition memory after incidental encoding in children with developmental dyslexia. PloS one, 8(5), 1-7.

Hengeveld, K., \& Leufkens, F. (2018). Transparent and Non-transparent Languages. Folia Linguistica, 52(1), 139-175

Komarova, Yu. A. (2013). Brilliant 2. Student's book. Moscow: OOO Russkoye slovo - uchebnik, Macmillan. 
Lalayeva, R. I. (2019). Reading Disorder and the Ways of Correcting it with primary school students. St. Petersburg: KARO.

Lenskaya, E. A. (1978). Problems of teaching reading in English to primary school children. Moscow: NII APN SSSR.

Leontyev, A. N. (2004). Activity. Consciousness. Personality. Moscow: Smysl, Akademia.

Ministry of Education of the Russian Federation. (2020). On the approval of the federal list of textbooks approved for use in the implementation of state-accredited educational programs of primary, basic, $\begin{array}{llll}\text { secondary general } & \text { Retrieved }\end{array}$ https://fpu.edu.ru/uploads/files/0110419444b9ff3f741d1a15002f696c.pdf

Passov, E. I., \& Kuzovleva, N. E. (2010). Fundamentals of communication theory and technology in foreign language education. Moscow: Russkii mir.

Rowse, H. J., \& Wilshire, C. E. (2007). Comparison of phonological and whole-word treatments for two contrasting cases of developmental dyslexia. Cognitive Neuropsychology, 24(8), 817-842.

Shaywitz, S. E. (2003). Overcoming dyslexia: A new and complete science-based program for reading problems at any level. New York: Knopf.

Shaywitz, S. E., Shaywitz, B. A., Fulbright, R. K., Skudlarski, P., Mencl, W. E., Constable, R. T., ... \& Gore, J. C. (2003). Neural systems for compensation and persistence: young adult outcome of childhood reading disability. Biological psychiatry, 54(1), 25-33.

Svirina, L. O. (2008) On the Communicative Approach to a Foreign Language Teaching by a Non-speaker. Vestnik TGGPU, 1(12), 70-73.

The British Dyslexia Association. (2020). Dyslexia. Retrieved from https://www.bdadyslexia.org.uk/dyslexia

Tridas, E. Q. (2007). From ABC to ADHD: What parents should know about dyslexia and attention problems. Baltimore: The International Dyslexia Association.

Vygotskii, L. S., Hanfmann, E., Vakar, G., \& Kozulin, A. (2012). Thought and Language. Cambridge, Mass.: MIT Press. 